\title{
Socializadas bajo el franquismo, rebeldes en la transicion, feministas siempre (Reflexiones sobre una obra de actualidad)
}

\author{
Rebeldes ilustradas (La otra \\ transición).
}

GARCÍA DE LEÓN, María Antonia.

Barcelona: Editorial Anthropos, 2008. $220 \mathrm{p}$.

He aquí una original contribución para una Memoria de Género en la sociedad española actual. Con estas Rebeldes ilustradas que nos ofrece ahora María Antonia García de León, la autora avanza un paso más en lo que aparece ya como un proyecto intelectual consolidado: la construcción de la memoria colectiva de unas generaciones de mujeres españolas que rompieron los moldes de género e introdujeron en España una nueva manera de ser mujer. Herederas $y$ heridas fue una primera indagación sobre la posibilidad y condición de este cambio, especialmente para las mujeres que dedicaron su vida a la Universidad y la investigación; su muy reciente Antropólogas, politólogas y sociólogas, de autoría compartida con María Dolores F. Figares, se plantea la indagación sobre qué ha ocurrido con las mujeres profesionales de las ciencias sociales, qué han hecho y qué han dejado en los ámbitos de sus especialidades. $Y$ formula ya claramente una pregunta relevante ¿qué quedará de nosotras cuando hayamos muerto? Un interrogante que inquieta a María Antonia y que, a través de ella, se transmite como un eco a unos colectivos de mujeres que están llegando al tiempo de los balances.

Una inquietud y una pregunta totalmente pertinentes. Los indudables logros de las mujeres españolas que vivieron la transición política, la necesidad de afirmar las victorias para dejar atrás los tonos plañideros y comenzar a ser por derecho propio, han enmascarado, probablemente, muchas de las debilidades de la situación. Ser investigadoras, catedráticas, autoras reconocidas, profesoras en universidades prestigiosas, ostentar cargos políticos, son condiciones sociales que, detentadas por hombres, aseguran algún lugar en la memoria colectiva. Tal vez no un nombre propio o una estantería en las grandes bibliotecas; pero sí, por lo menos, un renglón en los registros de la impronta generacional. Atareadas en ser, en hacer, en vivir, dimos por descontada la inscripción automática en esta memoria, como algo inherente a los puestos conseguidos. Y hoy empezamos a ver que no es así, que sigue sin ser lo mismo ser autor que autora, y que la voz de las mujeres, sean quienes sean, no se inscribe automáticamente en la historia común. Porque la escritura de esta historia no fue nunca automática, sino selección desde el poder.

Un poder que seguimos sin lograr.

Así que, nos dice la autora, no hay que esperar a que los futuros cronistas nos rescaten del olvido, sino que, como siempre para las mujeres, ponte tu misma a tejer tu traje y deja de esperar en vano al hada madrina. Y he aquí un nuevo fruto de este empeño: con Rebeldes ilustradas María Antonia nos ofrece una nueva reflexión polifónica y multidimensional, y sigue abriendo caminos para la construcción de una memoria generacional.

Una reflexión polifónica: como suele hacer en la mayoría de sus obras, también aquí María Antonia García de León se acompaña de otras voces. En este caso, voces directas, no ya cortadas temáticamente o como ilustraciones de determinadas tesis. El relato personal de la propia vida nada tiene que ver con la exhibición: es parte de la historia, siempre, y en determinados casos, parte de una historia tan especial y atípica que debe ser conservada para que en el futuro puedan entenderse las trayectorias comunes a partir de estas huellas. Mujeres muy conocidas, indispensables en la historia española de los sesenta, los setenta, los ochenta, los noventa, los dos mil, que han explorado territorios, han derribado barreras, han colonizado espacios antes inaccesibles. Que lo siguen haciendo: Celia Amorós, Paloma Gascón, Isabel Morán, Pilar Pérez Fuentes. Perfiles obligados para entender una etapa del cambio, porque además de construirlo con sus vidas, tienen el don de la palabra y la capacidad de la reflexión, de la comprensión de los cómos y los porqués. 
Tienen elaborada una narrativa que describe un mundo, una época, un antes y un después. $Y$ nos muestran, paso a paso, día a día, cómo avanzaron en el difícil aprendizaje de ser mujeres tradicionales primero, de dejar de serlo después, de asumir perfiles, responsabilidades, tareas, que en su niñez nunca pudieron figurar en su horizonte vital, y a las que, en cambio, hubo que lanzarse, gozosas y temblando, sin apenas modelos, asumiendo riesgos, muchos riesgos.

Y también una voz propia, la de María Antonia, en una interesante autoentrevista, con la que sienta un precedente curioso, en la línea de la emergencia del sujeto como centro de la reflexión. Un precedente no exento de riesgos, una vez más, porque ¿cómo establecer la dualidad, el diálogo, la distancia necesaria para esquivar la autocomplacencia, el narcisismo, la autojustificación? ¿Por qué no escribir directamente unas memorias personales, género de reglas conocidas que no pretende más verdad que la personal? Mi impresión es que María Antonia no está interesada en contarnos su vida, sino en extraer de ella, como material que tiene a mano, la narración de una experiencia común y al mismo tiempo irrepetible. $Y$ para ello, se desdobla en un diálogo consigo misma, en un alarde de duplicidad que nos hace olvidar que quien pregunta y quien responde es una misma persona. Sólo desde un hábito de distanciamiento largamente adquirido en la práctica de las ciencias sociales pueden tenerse ciertas garantías de objetividad en este tipo de ejercicio. Sólo desde el rigor de una mirada habituada a triturar la vida en la batidora de una metodología implacable es posible extraer de la propia experiencia categorías más universales que las del testimonio - la melancolía.

Polifonía, pues, pero también multidimensionalidad. Y es aquí donde Rebeldes ilustradas adquiere, en mi opinión, una amplitud de objetivos que la convierten en el libro más ambicioso de la autora.

He mencionado ya una primera dimensión: la de la voluntad de construcción de una memoria generacional en una etapa especialmente intensa. Para quienes la vivimos, todo suena a conocido. Pero vendrán otras, ya están aquí, que apenas pueden creerlo. "Me casaba en enero y no me dejaron salir en nochevieja", cuenta Celia. Un ejemplo entre tantos. Y cada una de nosotras podría contar decenas de anécdotas parecidas, que configuran un mundo que ya no existe. Cuando alguna española, en el futuro, tenga la tentación de la nostalgia, que relea estas páginas, para celebrar con euforia su presente, que tantas, antes de nosotras, murieron sin alcanzar.

Pero hay más, hay más. La dimensión política recorre el libro, que no por azar lleva como subtítulo "La otra transición". Efectivamente, la transición política española se ha considerado modélica, ha sido analizada, divulgada, ensalzada y hasta se ha intentado exportarla y copiarla. Pero ¿qué transición? Hubo tantas transiciones... Y la que ha sobrevivido, como siempre, fue la transición masculina, aquella a través de la cual una generación de hombres relevó a otra en el poder. Y, al realizar el relevo, no sólo cambiaron los nombres y las caras, sino las reglas de juego colectivas. ¿Quién va a negar su importancia?

Aquella transición, leída a menudo como una epopeya, fue posible porque culminó diversas transiciones. Que casi nunca fueron contadas. La transición de la clase trabajadora, por ejemplo, que pasó de clase en sí a clase para sí, para decir lo que quería y lo que no quería, y obligar así a cambiar las reglas de juego, porque había aprendido a usar en su favor las del franquismo y bloquear las fábricas cuando hiciera falta. O bloquear las escuelas, en un recuerdo para mí imborrable de miles de maestras en acción, utilizando incluso los sindicatos verticales cuando hizo falta. La transición de los partidos clandestinos, la transición de los estudiantes, la transición de los militares, la transición de los vencidos y de los exiliados, capaces de aceptar un paréntesis cuando hizo falta para pactar una nueva Constitución.

Y la transición de las mujeres, tal vez la más poderosa, tal vez la más olvidada. Como nos recuerda Anna Caballé en un magnífico prólogo, no había ninguna mujer entre los siete padres de la Constitución, y a nadie se le ocurrió sin embargo discutir su legitimidad. De hecho, todavía se está escribiendo una Constitución de la que formemos parte: las recientes leyes contra la violencia de género, por la igualdad, el proyecto que ahora mismo (invierno 2009) está en debate sobre la modificación de la ley del aborto, no son sino incorporaciones tardías a lo que debía haber sido una Constitución que contemplara la igualdad entre los dos sexos, la incorporación de las exigencias de los géneros y la desaparición de las barreras entre ellos. Porque esta transición se hizo, pero sin el suficiente reflejo en las leyes, en las normas colectivas. Como siempre, ello no era importante, podía esperar. Como ha sucedido en tantas transiciones, recordadas en este libro por Pamela Radcliff, Breny Mendoza y Amalia Rubio, en preciosas 
aportaciones que nos dan toda la dimensión política del tema.

En las grandes batallas, los hombres requieren el esfuerzo de las mujeres, su sacrificio, su tiempo y su energía, para lo que se presenta como una batalla para el bien común. Y dicen: "Tu causa es importante, pero debe esperar a que triunfe la mía. Después, todo se os dará por añadidura". Lo oímos entonces: su transición era inaplazable, la nuestra podía esperar. Por suerte, muchas no lo creyeron ya, y las transiciones se hicieron en paralelo, sin pedir permiso, sin esperarlo. Pero ahora todo ello debe consolidarse para que nunca pueda producirse una vuelta atrás.

Consolidar la presencia de las mujeres en el ámbito público, en la historia, en las decisiones que se toman respecto a la vida colectiva como una exigencia inaplazable. Para que, en adelante, quien quiera contar con las mujeres tenga que incluirlas, o atenerse a las consecuencias: por ejemplo, no recibir su voto. Quien quiera escribir la historia tenga que incluirlas, o atenerse a las consecuencias: ser desautorizado como autor androcéntrico y parcial. Porque la huella de las que fueron antes ya sea tan imborrable que los olvidos no tengan justificación ni disculpa alguna.

Gracias de nuevo, María Antonia García de León, por seguir en la brecha de una tarea necesaria, en la que, esperemos, muchas otras y muchos otros te sigan.

Marina Subirats Universitat Autònoma de Barcelona 